\title{
Paper Miniaturized Spectacles Shaped Tapered Slotted Patch Antenna for UWB Applications
}

\author{
M. Tarikul Islam, M. Samsuzzaman, M. Z. Mahmud, and M. T. Islam \\ Centre of Advanced Electronic and Communication Engineering, The National University of Malaysia, Malaysia
}

https://doi.org/10.26636/jtit.2018.115717

\begin{abstract}
A compact planner patch ultra-wideband (UWB) antenna is presented in this paper. The antenna configuration consists of a spectacles-shaped patch and a slotted ground plane. Different parameters are investigated for improving the antenna's properties and for achieving the preferred UWB band (3.1-10.6 GHz). The experimental and simulated results demonstrate that the proposed antenna acquires an operating bandwidth of $117 \%$ (3-11.5 GHz) with a stable omnidirectional radiation pattern, about $89 \%$ of average radiation efficiency and $4.2 \mathrm{dBi}$ of average gain with the maximum of $5.7 \mathrm{dBi}$ at $10.2 \mathrm{GHz}$.
\end{abstract}

Keywords- patch antenna, tapered ground, UWB, wireless communication

\section{Introduction}

The main problem with most antennas is that the size and the bandwidth of an antenna are contradictory features. The wider the bandwidth, the bigger the antenna. Therefore, a lot of research has been conducted to overcome this problem. Recently, adding a finite metal plane [1], inserting an additional stub to one side of the circular patch [2], adding steps to the lower edge of the patch, adding a slot to one side of the radiating element [3] have been described as methods used for increasing the operating bandwidth of elliptically and circularly planar monopole antennas.

The properties of the ultra-wideband (UWB) antennas can be improved also by changing the patch shape (rectangular, elliptical, circular, heart-shaped). Wider bandwidth can be also achieved by reducing dimensions of the ground plane [4]-[7]. Over the past decade, numerous antennas have been proposed for UWB applications. Unfortunately, a large ground plane increases bandwidth, but also increases the dimensions. Hence, the antenna is no longer compact and is hard to integrate with microwave technology [8]. To overcome this problem for UWB applications, various line-feeding and waveguide-feeding antennas are investigated.

Ray et al. reported a small elliptical ring antenna for UWB applications, where the antenna having a bandwidth of 4.6-10.3 GHz does not meet the requirements of UWB systems [2]. Despite its compact size, the antenna cannot offer a full range of UWB features [9], but its dimensions are smaller than those of the antennas reported in [10], [11].
In this paper, an antenna with a spectacles-shaped radiator and a tapered slot ground plane, with the operating bandwidth of 3-11.5 GHz and meeting all UWB criteria is presented. Its dimensions are reduced, but performance is increased due to the modified design structures. Combination of the spectacles-shaped patch and the tapered slot ground plane make the design more efficient and suitable for use in UWB applications.

\section{Design}

Figure 1 shows the proposed antenna layout to be fabricated with the use of typical FR4 $1.6 \mathrm{~mm}$ thick PCB laminate. The front side, having the form of a spectacles-shaped radiator, is shown in Fig. 1a. Figure $1 \mathrm{~b}$ shows the ground plane,

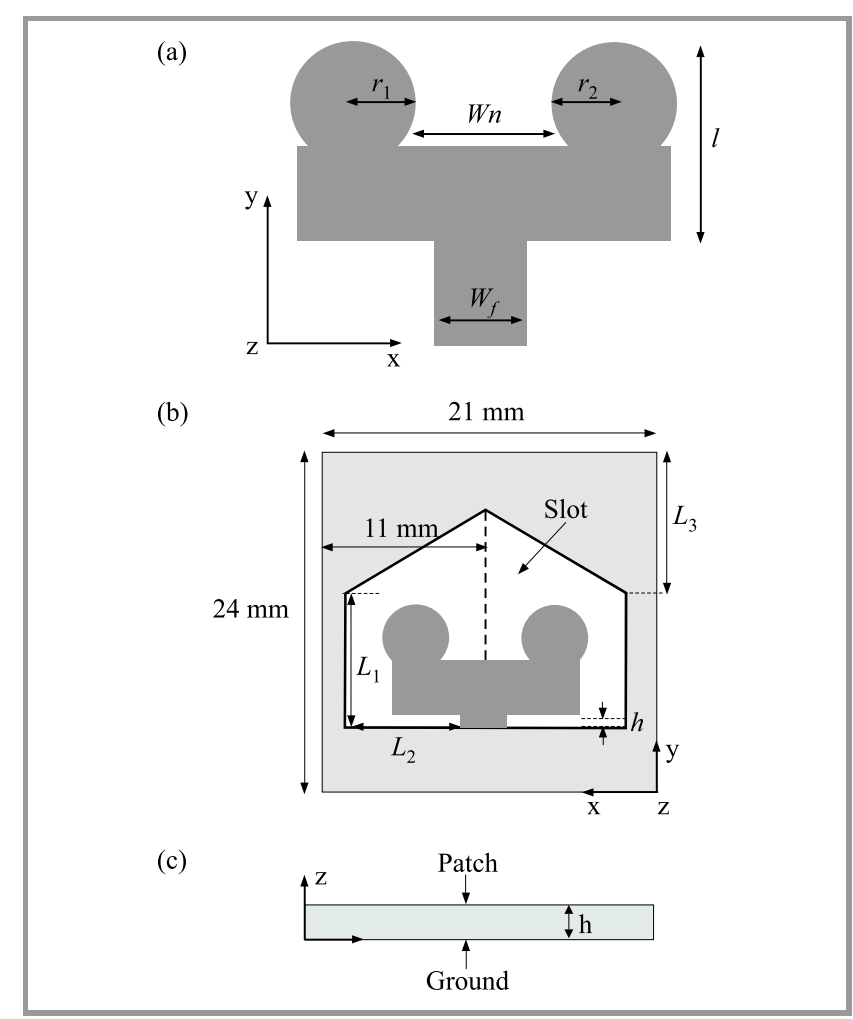

Fig. 1. Antenna geometry: (a) top view, (b) bottom view, (c) side view. 
which is calculated on the other side of FR4. Two circular slots $r_{1}$ and $r_{2}$ form the spectacles-shaped modified patch, ensuring better performance. A $50 \Omega$ microstrip transmission line is connected to the bottom of the feed line. The overall dimensions of the design are $(\mathrm{W} \times \mathrm{L}) 21 \times 24 \mathrm{~mm}$. The specific parameters of the modified ground plane and patch are presented in Table 1.

Table 1

Parameter of the presented design

\begin{tabular}{|c|c|c|c|}
\hline Parameter & $\begin{array}{c}\text { Value } \\
{[\mathrm{mm}]}\end{array}$ & Parameter & $\begin{array}{c}\text { Value } \\
{[\mathrm{mm}]}\end{array}$ \\
\hline \hline$W$ & 21 & $w_{1}$ & 6.5 \\
\hline$L$ & 24 & $L_{1}$ & 8.66 \\
\hline$l$ & 7.30 & $L_{2}$ & 7.52 \\
\hline$W_{n}$ & 5.56 & $L_{3}$ & 10.12 \\
\hline$W_{f}$ & 3 & $h$ & 1.6 \\
\hline$r_{1}, r_{2}$ & 2.5 & $h_{1}$ & 5.564 \\
\hline
\end{tabular}

Different shapes tested in order to achieve a wide UWB bandwidth are shown in Fig. 2a and simulated results of $\mathrm{S}_{11}$ are presented in Fig. 2b. It is observed that the tapered design offers a wider bandwidth compared to circle, elliptical or square slot ground planes. For the circle slot ground

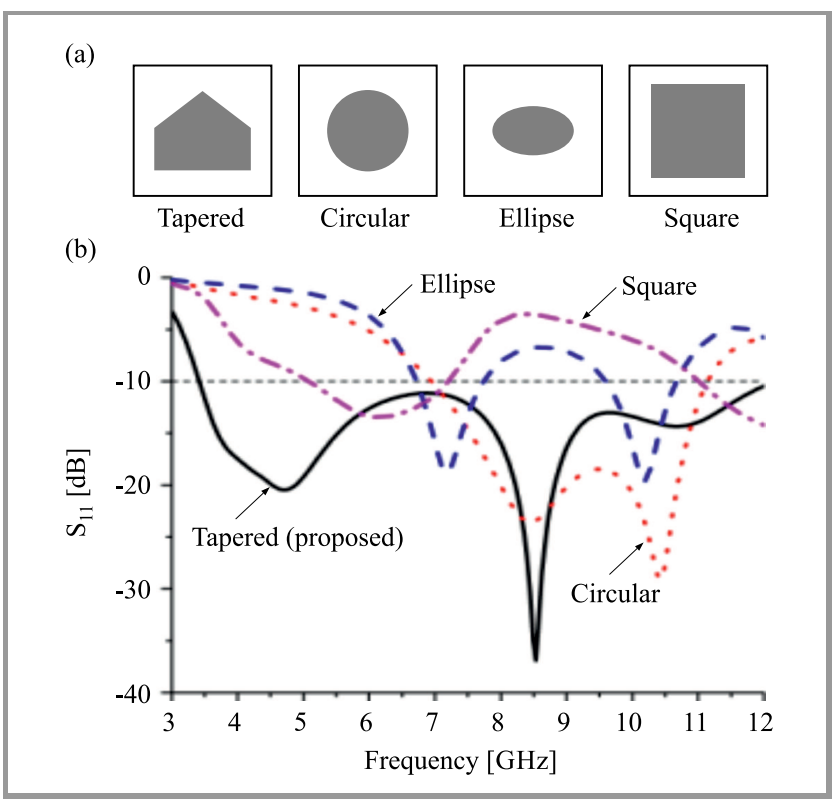

Fig. 2. Effect of ground plane shape on $\mathrm{S}_{11}$ : (a) different ground plane shapes and (b) $S_{11}$ parameter.

plane, the operating bandwidth achieved is $7.3-11 \mathrm{GHz}$ and fails to meet UWB requirement. For elliptical and square slot ground planes, the resonant frequency is not satisfactory to meet the desired specification. Finally, after applying the tapered slot ground plane, the operating bandwidth attained $(<10 \mathrm{~dB})$ meets the requirements set. Figure 3 demonstrates the effect of patch shape on bandwidth.

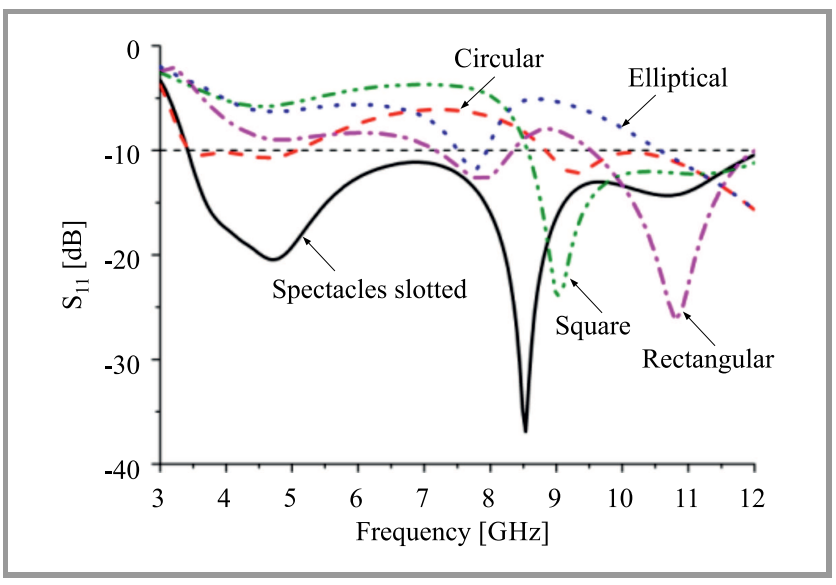

Fig. 3. Effects of patch shape on $S_{11}$ reflection coefficient.

The simulated results show that only the spectacles-shaped patch proposed attains a full bandwidth of 3-11.5 GHz, covering the entire UWB spectrum. The lower frequency bandwidth is meaningfully affected by the modified patch shape.

\section{Results}

\subsection{Frequency-Domain Performance}

A prototype of the proposed antenna is presented in Fig. 4. The optimization measurements were performed with $3 \mathrm{D}$ HF Ansoft's HFSS EM software simulator, based on the finite element method and the CST Studio solver. The results

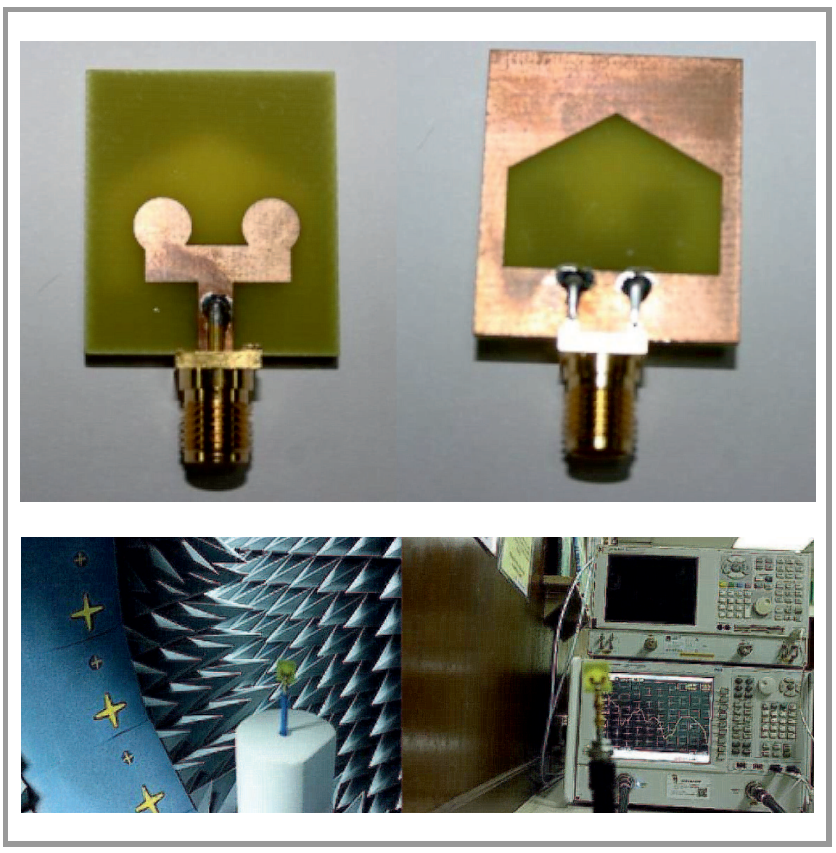

Fig. 4. Prototype of the proposed antenna (top and bottom view) difference and measurment setup.

measured were attained from the Agilent E8362C vector network analyzer in a Satimo near field anechoic chamber (UKM StarLab). 
The reflection coefficient $S_{11}$, measured and simulated vs. frequency is shown in Fig. 5. It is observed that the operating bandwidth ranges from 3 to $11.5 \mathrm{GHz}$. There is a slight distortion between the measured and simulated results, because of faulty soldering and the coaxial cable that was used for the measurements. The design covers the full UWB band (3.1-10.6 GHz).

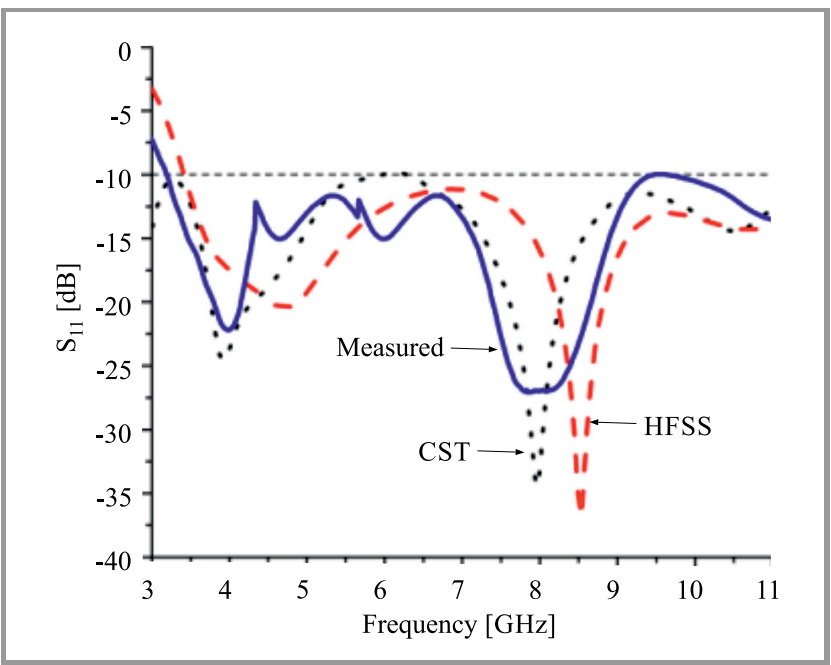

Fig. 5. Return loss vs. frequency.

The simulated and experimental gain across the operating bandwidth is presented in Fig. 6. The maximum gain of $5.7 \mathrm{dBi}$ is recorded at $10.2 \mathrm{GHz}$, and the average gain across UWB equals $4.2 \mathrm{dBi}$. The radiation efficiency measured and simulated for the antenna is presented in Fig. 7. Radiation varies between lower and higher bands from $81 \%$ to $9 \%$. Efficiency and gain are both affected by the use of low-cost FR4 PCB laminate as the substrate. Gain and efficiency can be improved by using microwave substrate materials.

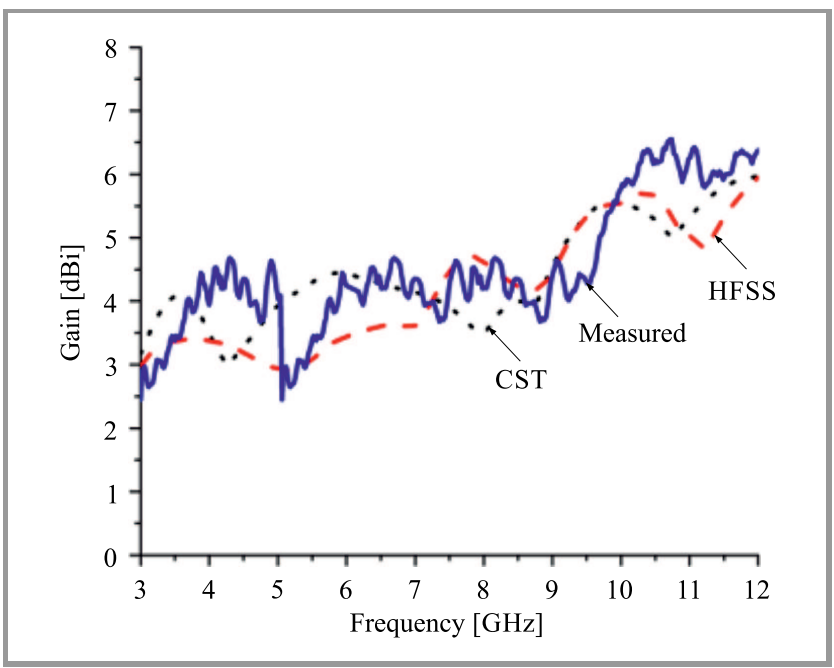

Fig. 6. Measured and simulated gain.

The surface current distribution at $4.5 \mathrm{GHz}$ and $8.5 \mathrm{GHz}$ is shown in Figs. 8 and 9, respectively. The antenna's

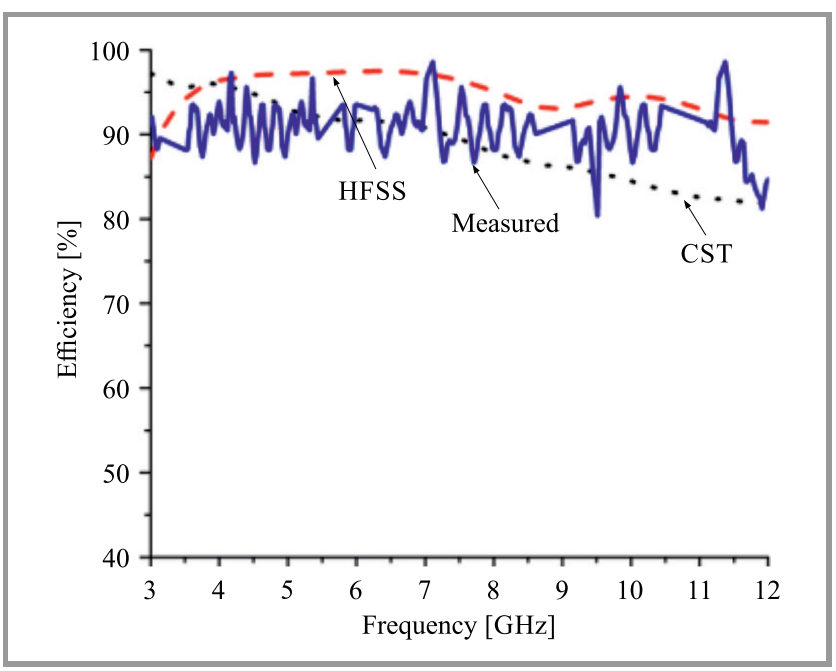

Fig. 7. Measured and simulated efficency.

(a)

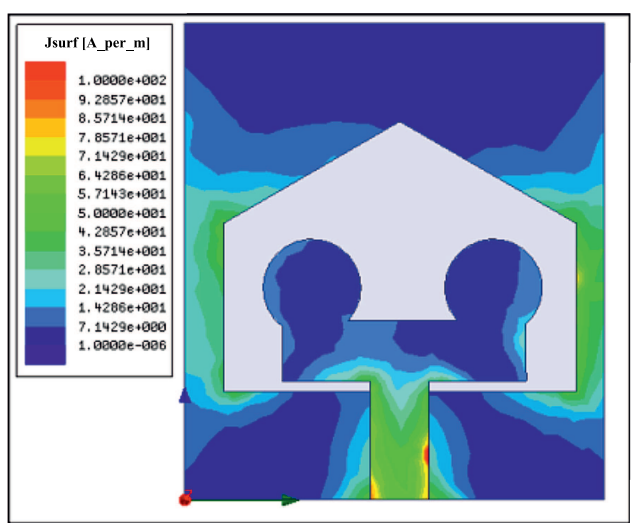

(b)

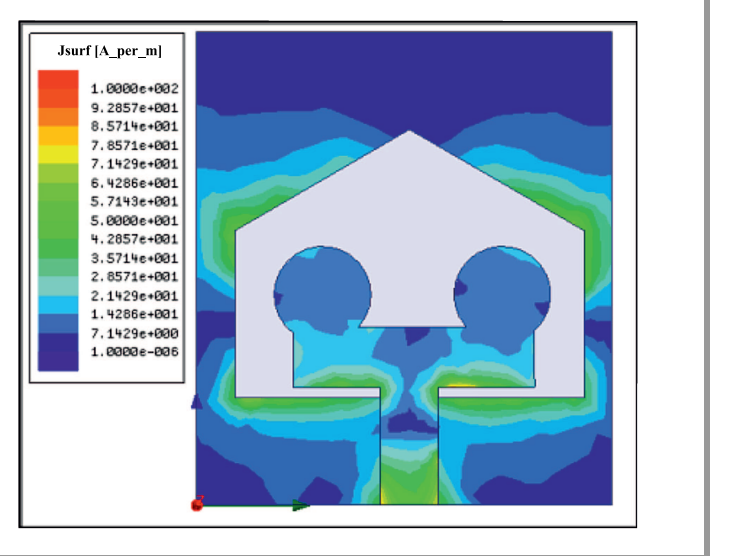

Fig. 8. Surface current distribution at: (a) $4.5 \mathrm{GHz}$ and (b) $8.5 \mathrm{GHz}$. (See color pictures online at www.nit.eu/ publications/journal-jtit)

measured and simulated radiation pattern at $3.5 \mathrm{GHz}$, 6.5 $\mathrm{GHz}$ and $9.5 \mathrm{GHz}$ with both cross-polarization and co-polarization of two major planes, is shown in Fig. 9. The surface current is evenly distributed over the lower frequency of $4.5 \mathrm{GHz}$. At higher frequencies, the antenna shows the development of higher order current modes and the density of current is lower on the patch. It is observed that the antenna has, over the UWB band, a stable radiation 
pattern that is almost omnidirectional at lower frequencies. Unwanted cross-polarization occurs with the increase of frequency when changing current distribution. As a result, the radiation pattern is slightly more directional at higher frequencies. Several null points are also observed in current distribution at higher frequencies. With higher order modes, the radiating element is excited and causes the directional radiation pattern. (a)

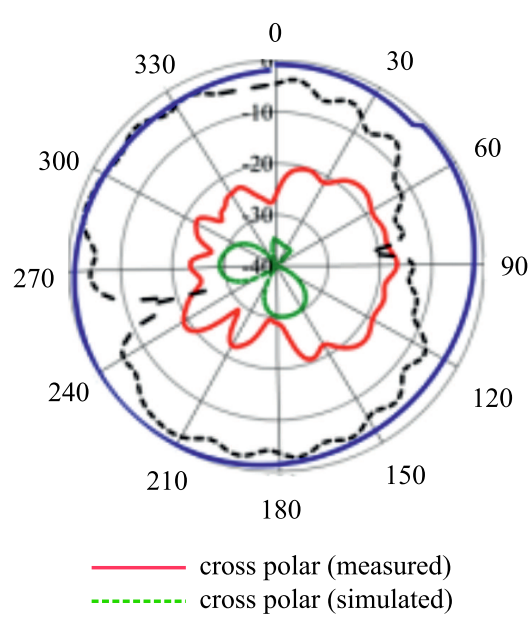

(b)

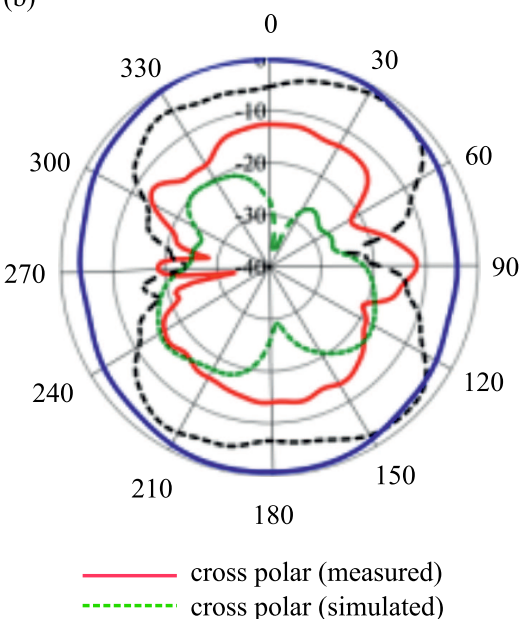

(c)

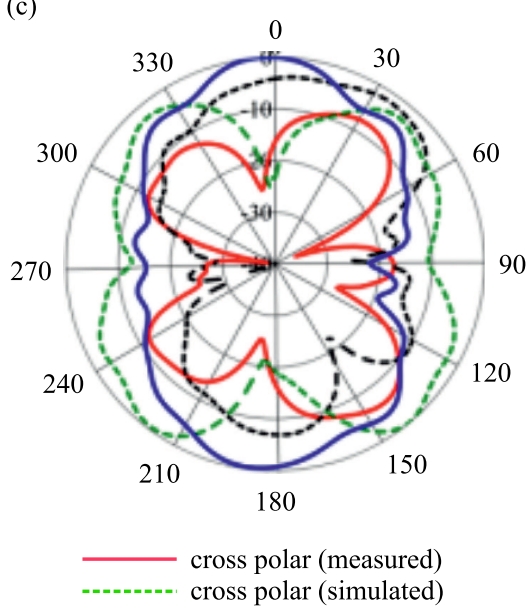

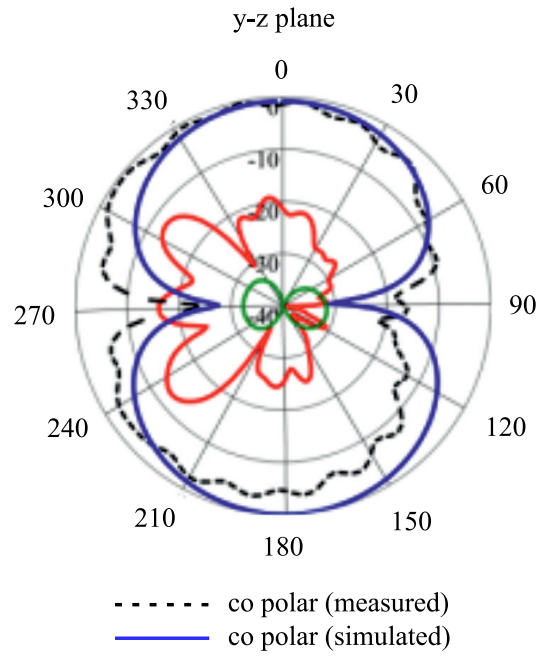
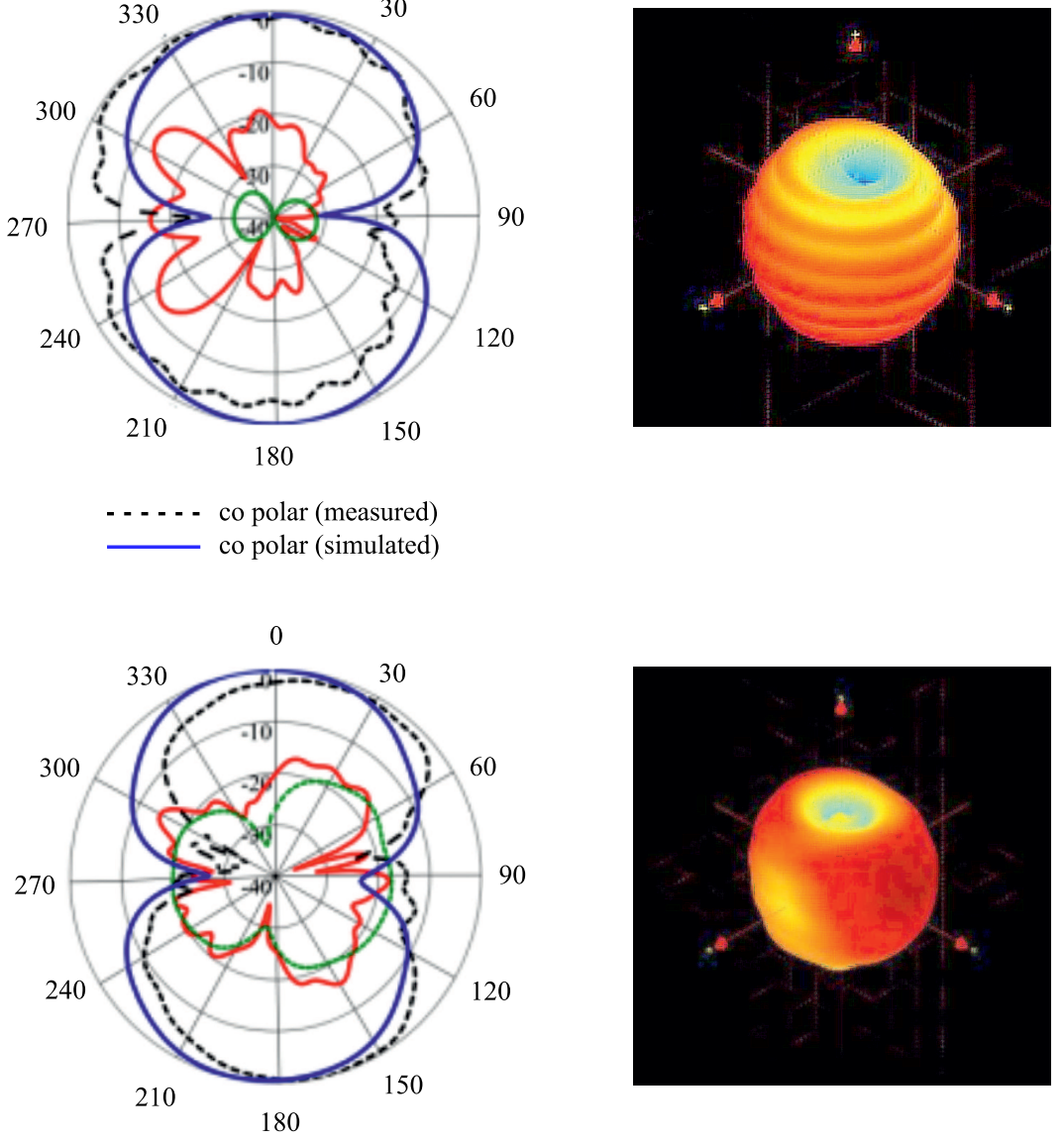

- . - . - co polar (measured) co polar (simulated)

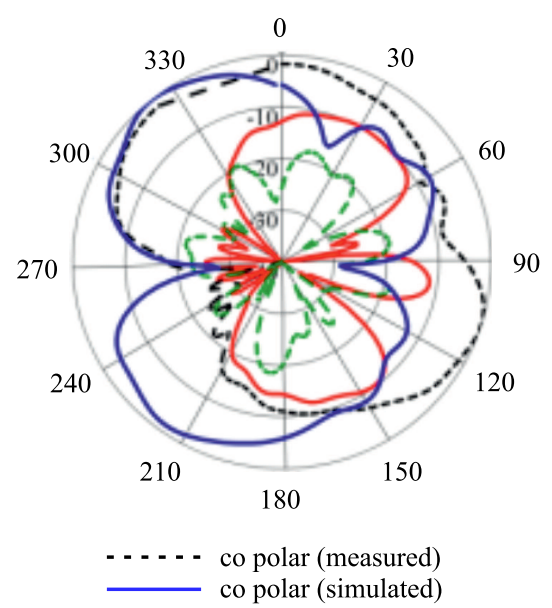

Fig. 9. 2D and 3D radiation pattern at: (a) $3.5 \mathrm{GHz}$, (b) $6.5 \mathrm{GHz}$, and (c) $9.5 \mathrm{GHz}$. 


\subsection{Time Domain Performance}

It is clear, from frequency domain observations, that the proposed antenna demonstrates good frequency domain performance. However, decent frequency domain characteristics cannot guarantee the antenna's equal behavior in the time domain. Hence, in order to validate the design, its time-domain behavior needs to be examined, including the transmission coefficient, input-output pulse waveform, and group delay investigation. Figure 10 shows the transmission coefficient $\left|S_{21}\right|$ with two matching proposed antennas used, placed in front of each other and in a sideby-side configuration, at a distance of $300 \mathrm{~mm}$, considering far field environments across the whole UWB range. Figure 10 shows flat magnitude of the transmission coefficient line over the operating band. A slight decrease is observed in the side-by-side scenario at $10.1 \mathrm{GHz}$, with the magnitude remaining flat over the rest of the bandwidth, which indicates a stable UWB transmission capability in both face-to-face and side-by-side configurations.

The group delay is defined as the first derivative of the far field phase of the transmission response with respect to radial frequency $\omega$ [12]. Figure 11 presents the measured

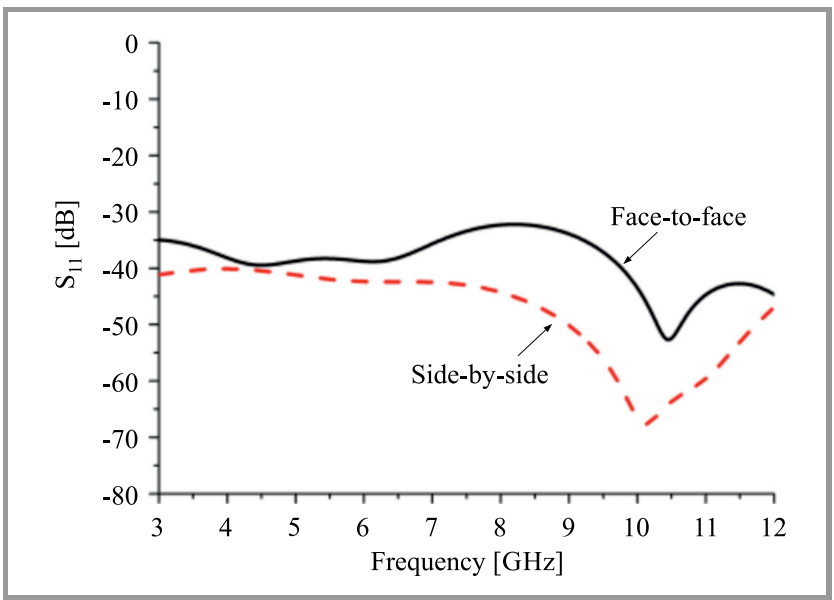

Fig. 10. Transmission coefficient in face-to-face and side-by-side scenarios.

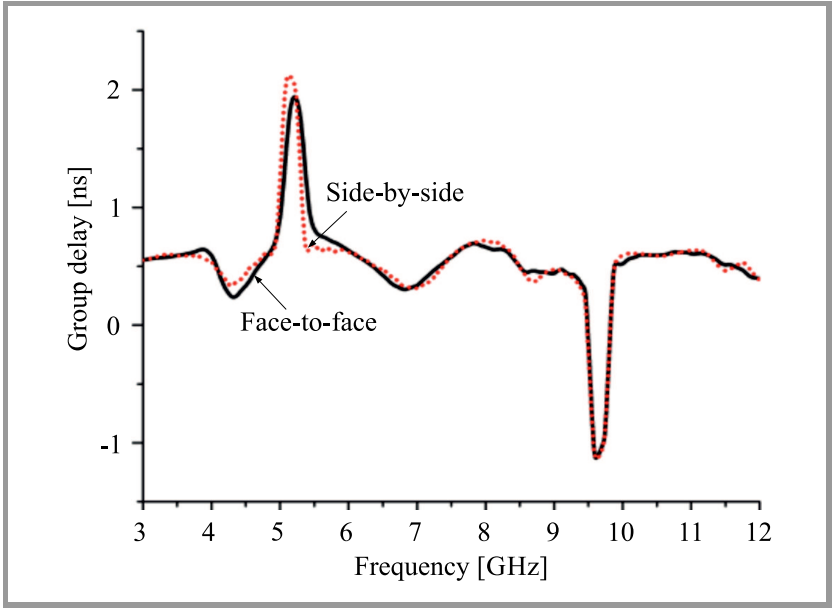

Fig. 11. Group delay. group delay in the face-to-face and side-by-side scenarios. One can see two sharp variations of the group delay at 4.5 and $8.5 \mathrm{GHz}$, which specifies a slight non-conformity with the linear phase response. Group delay remains almost constant at other frequencies outside the affected bands that show good phase linearity. The input and received signals in the face-to-face and side-by-side scenarios (with the distance of $300 \mathrm{~mm}$ in the case of the latter) are shown in Fig. 12. The received signals in both orientations have par-

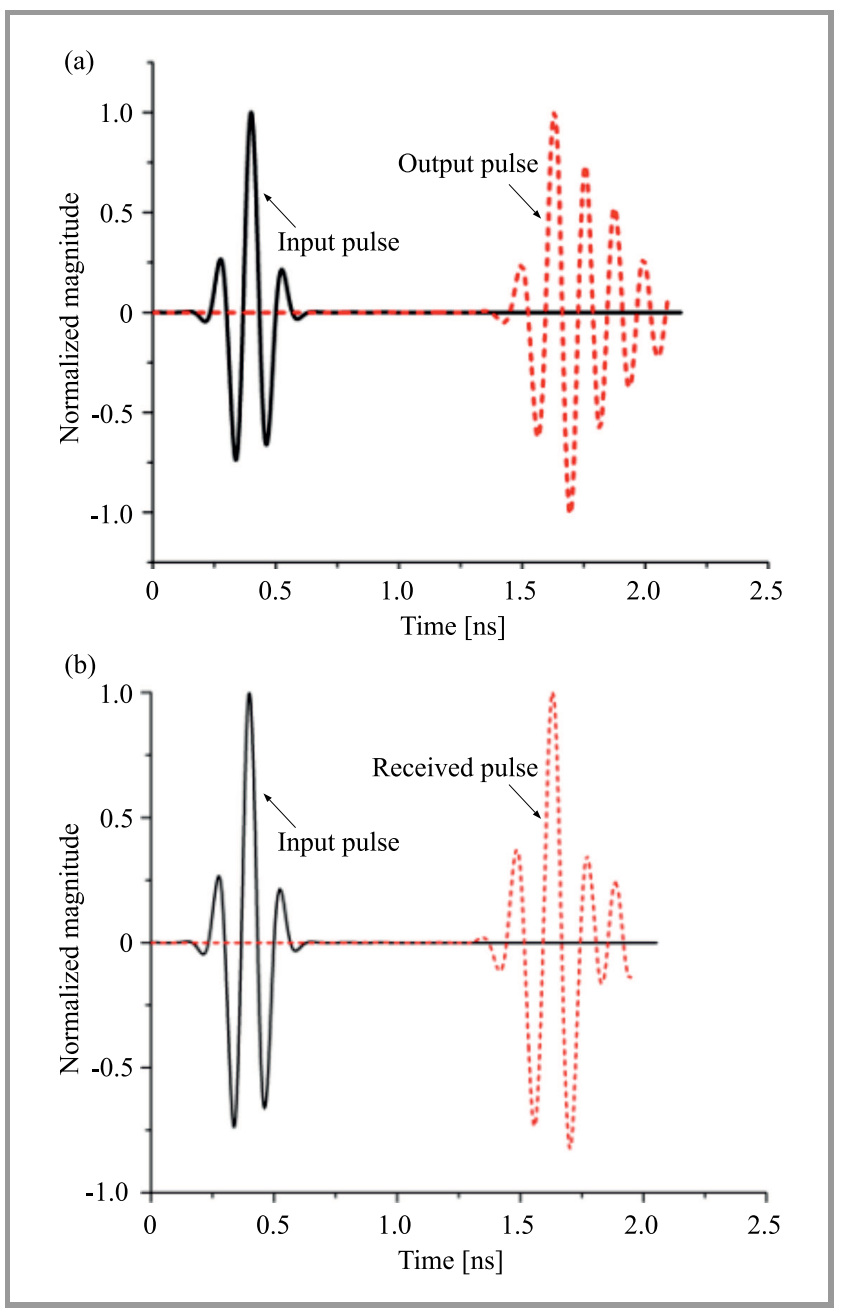

Fig. 12. Input and received pulse waveforms in: (a) face-to-face and (b) side-by-side scenario.

allel waveforms showing a small disparity. The highest value of cross-correlation between the transmitting and receiving pulse estimates the signal distortion, known as fidelity factor (FF). Typically, the pulse becomes almost unrecognizable if the alteration is higher than $50 \%(\mathrm{FF}<0.5)$. For face-to-face and side-by-side setups, FF equals $83 \%$ and $90 \%$, which indicates that the proposed system offers a lower distortion of the signal while transmitting UWB impulse signals, simultaneously displaying a low-variation transmission coefficient, a constant group delay and a decent FF, demonstrating good phase linearity.

A comparison of the proposed antenna and the ones described in literature is presented in Table 2. The parameters 
considered include bandwidth (BW), fractional bandwidth (FBW), gain, and applications.

Table 2

Comparison of bandwidth, fractional bandwidth, gain, and applications

\begin{tabular}{|c|c|c|c|c|}
\hline Reference & $\begin{array}{c}\text { BW } \\
\left(\mathrm{S}_{11}<\right. \\
10 \mathrm{~dB}) \\
{[\mathrm{GHz}]}\end{array}$ & $\begin{array}{c}\text { FBW } \\
{[\%]}\end{array}$ & $\begin{array}{c}\text { Gain } \\
{[\mathrm{dBi}]}\end{array}$ & $\begin{array}{c}\text { Applica- } \\
\text { tions }\end{array}$ \\
\hline \hline$[8]$ & $3.4-9.9$ & 97 & 4.8 & $\begin{array}{c}\text { Near } \\
\text { field } \\
\text { imaging }\end{array}$ \\
\hline$[5]$ & $4-14$ & 111 & $2.32-4.4$ & UWB \\
\hline$[6]$ & $3.7-18$ & 132 & 3.97 & UWB \\
\hline$[7]$ & $3.1-15.2$ & 132 & 2.5 & UWB \\
\hline$[9]$ & $8.39-9.7$ & 84 & 4.25 & UWB \\
\hline $\begin{array}{c}\text { Proposed } \\
\text { design }\end{array}$ & $3-11.5$ & 117 & 5.7 & UWB \\
\hline
\end{tabular}

\section{Conclusions}

The spectacles-shaped patch antenna is a miniature $21 \times 24 \mathrm{~mm}$ design with an operating bandwidth of $117 \%$ $(3-11.5 \mathrm{GHz})$ and a return loss of $<10 \mathrm{~dB}$. The antenna shows an average peak gain of $4.2 \mathrm{dBi}$ across the UWB band, with high efficiency levels of over $81 \%$ and a stable omnidirectional radiation pattern. Both the frequency and time domain characteristics of the proposed design are properly analyzed. The antenna is very simple in design, low-cost and highly efficient, which makes it suitable for integration with portable devices.

\section{References}

[1] H. Nazli, E. Bicak, B. Turetken, and M. Sezgin, "An improved design of planar elliptical dipole antenna for UWB applications", IEEE Antennas and Wireless Propag. Let., vol. 9, pp. 264-267, 2010.

[2] K. Ray and Y. Ranga,"Ultrawideband printed elliptical monopole antennas", IEEE Transact. on Antennas and Propag., vol. 55, no. 4, pp. 1189-1192, 2007.

[3] K.-H. Kim and S.-O. Park, "Analysis of the small band-rejected antenna with the parasitic strip for UW", IEEE Transact. on Antennas and Propag., vol. 54, no. 6, pp. 1688-1692, 2006.

[4] M. Sharma and V. Shrivastava, "Printed fractal elliptical monopole antenna for UWB application", in Proc. 2008 Int. Conf. of Recent Advances in Microwave Theory and Appl. Microwave-08, Jaipur, Rajasthan, 2008, pp. 374-376.

[5] A. A. Shaalan and M. Ramadan, "Design of a compact hexagonal monopole antenna for ultra-wideband applications", J. of Infrared, Millimeter, and Terahertz Waves, vol. 31, no. 8, pp. 958-968, 2010.

[6] L. Liu, S. Cheung, R. Azim, and M. T. Islam, "A compact circularring antenna for ultra-wideband applications", Microwave and Optic. Technol. Let., vol. 53, no. 10, pp. 2283-2288, 2011.

[7] Y. B. Yang, F. S. Zhang, F. Zhang, L. Zhang, and Y. C. Jiao, "A novel compact CPW-fed planar monopole antenna with modified stair-style ground for ultra-wideband application”, Microwave and Optic. Technol. Let., vol. 52, no. 9, pp. 2100-2104, 2010.
[8] M. N. Shakib, M. T. Islam, and N. Misran, "Stacked patch antenna with folded patch feed for ultra-wideband application", IET Microwaves, Antennas \& Propagation, vol. 4, no. 10, pp. 1456-1461, 2010.

[9] M. Islam, M. T. Islam, and M. R. I. Faruque, "Design of an UWB patch antenna for dual frequency operations", Research J. of Applied Sc., Engineer. and Technol., vol. 7, no. 4, pp. 822-825, 2014.

[10] M. Hossain, M. R. I. Faruque, and M. T. Islam, "Design of a patch antenna for ultra wide band applications", Microwave and Optic. Technol. Let., vol. 58, no. 9, pp. 2152-2156, 2016.

[11] K. Kikuta and A. Hirose, "Compact folded-fin tapered slot antenna for UWB applications", IEEE Antennas and Wireless Propag. Let., vol. 14, pp. 1192-1195, 2015.

[12] Y. J. Cho, K. H. Kim, D. H. Choi, S. S. Lee, and S.-O. Park, "A miniature UWB planar monopole antenna with $5-\mathrm{GHz}$ bandrejection filter and the time-domain characteristics", IEEE Transact. on Antennas and Propag., vol. 54, no. 5, pp. 1453-1460, 2006.

[13] G. Quintero, J.-F. Zurcher, and A. K. Skrivervik, "System fidelity factor: A new method for comparing UWB antennas", IEEE Transact. on Antennas and Propag., vol. 59, no. 7, pp. 2502-2512, 2011.

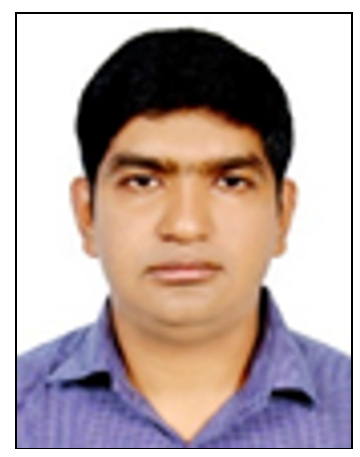

M. Tarikul Islam received his B.Sc. in Computer Science and Engineering from Patuakhali Science and Technology University (PSTU) in 2016. Currently he is working as an M.Sc. student at the National University of Malaysia (UKM), Malaysia. He has authored or co-authored a number of referred journals and conference papers. He is currently a Graduate Research Assistant at the Department of Electrical, Electronic and Systems Engineering, UKM, Malaysia. His research interests include communication antenna design, wireless communication, RF engineering and microwave imaging.

E-mail: p94299@siswa.ukm.edu.my

Centre of Advanced Electronic and Communication Engineering

The National University of Malaysia

Malaysia

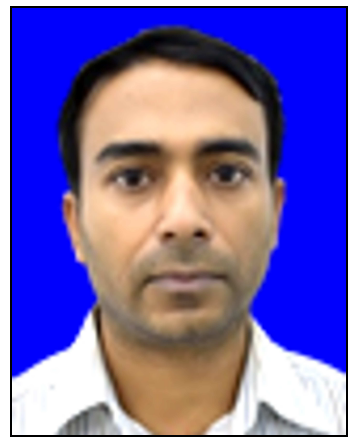

M. Samsuzzaman received his B.Sc. and M.Sc. degrees in Computer Science and Engineering from the Islamic University Kushtia, Bangladesh in 2005 and 2007, respectively, and the Ph.D. degree from the National University of Malaysia, Malaysia in 2015. Between 2008 and 2011, he worked as a Lecturer at the Patuakhali Science and Technology University (PSTU), Bangladesh. From February 2011 to 2015, he worked as an Assistant Professor at the same university. He is also an Associate Professor at the same university and is currently working as a post-doctoral fellow at the National University of Malaysia, Malaysia. He has authored or co-authored 
70 referred journals and conference papers. His research interests include communication antenna design, satellite antennas and satellite communication.

E-mail: samsuzzaman@ siswa.ukm.edu.my

Centre of Advanced Electronic and Communication Engineering

The National University of Malaysia

Malaysia

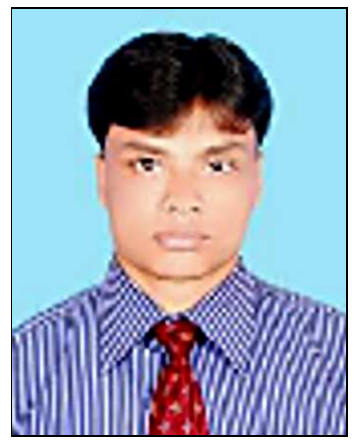

M. Zulfiker Mahmud is an Assistant Professor at the AIS Department of Jagannath University Bangladesh. He received his B.Sc. and M.Sc. degrees in Computer Science and Engineering from the Islamic University Kushtia, Bangladesh. Currently, he works as a Ph.D. student at the National University of Malaysia (UKM), Malaysia. He is currently a Graduate Research Assistant at the Department of Electrical, Electronic and Systems Engineering, UKM, Malaysia. He has authored or coauthored 25 referred journals and conference papers. His research interests include microwave imaging, antenna design, satellite antennas, satellite communication, and wireless communication.
E-mail: zulfikerm@siswa.ukm.edu.my

Centre of Advanced Electronic and Communication Engineering

The National University of Malaysia

Malaysia

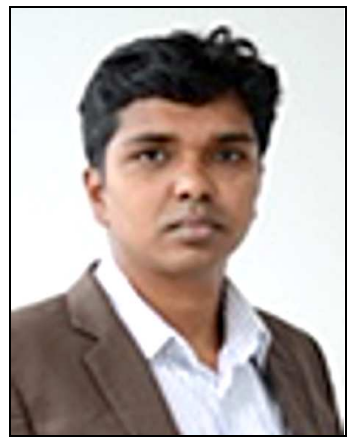

M. Tariqul Islam is a Professor at the Department of Electrical, Electronic and Systems Engineering of the National University of Malaysia (UKM) and a visiting Professor of Kyushu Institute of Technology, Japan. He has authored about 350 research journal articles, nearly 165 conference articles, 4 research level books and a few book chapters on various topics related to antennas, microwaves and electromagnetic radiation analysis with 13 inventory patents filed. $\mathrm{He}$ is a Senior Member of IEEE, a Chartered Professional Engineer (CEng), a Member of IET (UK) and a member of IEICE (Japan).

E-mail: tariqul@ukm.edu.my

Centre of Advanced Electronic and Communication Engineering

The National University of Malaysia

Malaysia 